\title{
POSOLOGY \\ (OR, HOW TO READ A READER)
}

When I took charge of compiling a Reader on camp, I accepted the both gratifying and challenging task of selecting 26 essays from the by now abundant bulk of critical writings (exceeding 1000 items) on camp; and the arbitrariness of all selection, the provisionality and partial character of all forms of canonicity is made even more poignant when related to an issue, camp, which combines its recent and still precarious institutionalisation (of which a Reader is in itself a sign) with its enacting a restless questioning of the very process of canonisation. I have thus tried to select not just those that seemed to be 'the best essays', with a valutative choice that inevitably reflects my own particular critical interests and may not be shared by all readers, but rather to select the best and/as most significant essays, that is to say the essays that have marked the critical apprehensions of the camp issue, each of them representing a whole nexus, or paradigm, of 'performance of camp' on the epistemic stage. Of course, this strategy hasn't prevented some very painful exclusions, and I have tried in the introductory sections to account, as far as possible, for many appreciable interventions that haven't been included here.

This Reader, being structured in a volume-bound cognitive order, can't exploit the illusory 'freedom' of hypertextual reading, and it retains a linear organisation that has to be briefly explained here. While the Introduction addresses the broader scope of the definitional enterprise by way of a metaphorical suggestion, the volume is divided into five sections, which are in part chronologically, in part thematically, arranged, but which - as the definitional assumption I formulate in the Introduction suggests - constitute a whole, however twisted and processual, building, with various epistemic and historical (the two being inextricable) 'wings' representing that queer discursive architecture which I claim camp may be taken for. Needless to say, when you visit the Louvre in Paris you are not required to visit the whole of it, and at once, nor to appreciate with the same intensity and pleasure all the rooms and exhibitions hosted there. But I trust many readers will find it worthwhile to stop here, and for more than one day.

I made an effort to reprint all the essays without deletions, just as they were first published, and when that was unavoidable, I asked the authors (namely, Linda Mizejewski and Carole-Anne Tyler) to make the cuts personally, or (in 
Pamela Robertson's case) to approve the extract. And I have not modified the original (US or British) spelling, for the localising effect that spelling may produce should be taken as a denaturalization, if there needs be one, of the specific framework in which the writings came into being. The one and only intervention I made on the essays is in the reference system, which all the essays now share. As the 'Digging the Scene' chronological bibliography closing this volume hosts virtually the totality of critical writings on camp, and the vast majority of works quoted in the included essays, it seemed advisable to combine an economic organisation of bibliographic space with the usefulness of a bibliography as a single, and exhaustive, overview of the critical corpus on the issue. All the items on camp are therefore referred to with the author-date system, and should be traced in that final bibliography, whereas the full reference to the items cited with the author, or author-title system, can be found in the 'References' section closing the single essays. 
Un peu trop, pour moi c'est assez.

-Jean Cocteau

If primates have a sense of humor, there is no reason why intellectuals may not share in it.

-William Plank, 'Ape and écriture: The Chimpanzee as PostStructuralist' (1989) 